\title{
VI Reunião Brasileira de Ensino e Pesquisa em Arquivologia - Trabalhos de Conclusão de Curso, Dissertações e Teses
}

A escrita deste editorial trata-se de um fechamento de gestão da Coordenação do Fórum de Ensino e Pesquisa em Arquivologia (FEPARQ), biênio 2018-2019, um processo de muito aprendizado, luta interior, manifestos, cartas e efetiva realização da Reunião Brasileira de Ensino e Pesquisa em Arquivologia (REPARQ) e de seus desdobramentos. A premiação da REPARQ - FEPARQ iniciou-se em 2017 como um incentivo à produção acadêmica nos três níveis de formação em Arquivologia. Essa prática continuou em 2019 e os artigos aqui reunidos representam pesquisas importantes e interessantes que foram produzidas durante os anos de 2017 e 2018.

A VI REPARQ foi realizada em Belém - PA entre 04 a 06 de setembro de 2019. Foram apresentados trabalhos, palestras e mesas redondas, além de reuniões específicas e premiação de trabalhos. A seleção dos trabalhos premiados ocorreu com a formação de três comissões distintas para avaliar cada modalidade, formadas por professores que atuam na área de Arquivologia no Brasil. Dos Trabalhos de Conclusão de Curso foram submetidos 15 trabalhos, com três trabalhos premiados. Já das dissertações foram submetidos oito trabalhos, sendo dois premiados e, as teses foram submetidas três e uma premiada. Os critérios de avaliação constavam nas chamadas para a premiação, as temáticas de pesquisas apresentadas foram as mais diversas, mas todas dentro do espectro teórico-metodológico da Arquivologia. A quantidade de trabalhos recebidos destaca-se não só a importância da premiação, mas o incremento ocorrido nos últimos anos no universo da pesquisa na Arquivologia brasileira.

Em nome da Comissão Organizadora, agradecemos a parceria com a Ciência da Informação em Revista e, em especial, a Prof. Dr. Edivanio Duarte de Souza, por todo apoio ao longo deste trabalho.

Os cinco artigos selecionados trabalham com temáticas fundamentais no escopo dos conceitos e funções arquivísticas, em realidades variadas. Começando com o artigo de Welder Antônio Silva e Renato Pinto Venâncio da UFMG: "Percepções e considerações sobre a informação pessoal nos arquivos: os estudos de alguns arquivistas no cenário internacional", tese premiada da FEPARQ - REPARQ, os autores buscam contribuir para as reflexões, no âmbito da Arquivologia e da Ciência da Informação, em torno do justo equilíbrio entre o direito de acesso à informação e os direitos à vida privada, à intimidade, à honra e à imagem.

Seguindo com a "Gestão de Informações Pessoais (PIM) em perspectiva: contribuições para o tratamento de arquivos pessoais digitais" de Jorge Phelipe Lira de Abreu, da UniRio, Aline Lopes de Lacerda e Luciana Quillet Heymann, ambas da FioCruz, dissertação premiada da FEPARQ - REPARQ, os autores buscaram estudos em Gestão de Informações Pessoais (PIM) como indicadores de comportamento na criação, manutenção, avaliação, seleção e preservação de arquivos pessoais digitais, bem como esses estudos podem contribuir para o tratamento e desses arquivos.

Já o artigo "A abordagem da difusão arquivística nos artigos de periódicos científicos A1 das áreas do conhecimento 'Comunicação e Informação' e 'Educação' da CAPES” de autoria de Fernanda Frasson Martendal e Eva Cristina Leite da Silva, da UFSC. Dissertação premi- 
ada da FEPARQ - REPARQ, em segundo lugar. Buscou identificar a abordagem da difusão arquivística no escopo da literatura em Arquivologia, Ciência da Informação e Educação. Contextualizando a difusão arquivística como função central para os arquivos atuais e vinculada diretamente com aspectos culturais e educativos, que fazem do arquivista um formador, das práticas no arquivo um processo de ensino-aprendizagem e do usuário. Como resultados tentou comprovar a tendência do arquivo de tornar-se um espaço cada vez mais social, para e pelos usuários da informação.

Dando início aos Trabalhos de Conclusão de Curso, o trabalho premiado em primeiro lugar pela FEPARQ - REPARQ intitulado "Olhares cegos: transformando fotografias em sons - a importância da audiodescrição no acesso à informação por usuários com deficiência visual" de autoria Evanildo Freitas do Nascimento Júnior, Carla Mara da Silva e Luiz Antonio Santana da Silva, todos da UFAM. Discute a temática da acessibilidade, por meio da revisão de literatura elucidou os desafios do arquivista na inclusão informacional de usuários com deficiência visual, através do método da audiodescrição como fonte de acessibilidade para estes. Os resultados foram analisados qualitativamente e discutidos com base na fundamentação teórica e a partir desses é proposto que o método de descrição de fotografias de Miriam Manini (2013) pode viabilizar o processo de realização da audiodescrição, garantido assim o direito de acesso e inclusão informacional aos portadores de deficiência visual.

Por fim, o Trabalho de Conclusão de Curso premiado em segundo lugar pela FEPARQ - REPARQ intitulado "A divulgação de acervos arquivísticos na web: potencialidades da perspectiva de user experience aplicada ao Sistema de Informações do Arquivo Nacional" com autoria de Bianca da Costa Maia Lopes e Eliezer Pires da Silva, da UniRio. Os autores discutem o fenômeno de uma nova geração de instrumentos arquivísticos de referência, a partir do caso do Sistema de Informações do Arquivo Nacional (SIAN), principal instrumento de referência disponibilizado pelo Arquivo Nacional, sob a ótica de User Experience (UX) Design. Parte-se de revisão bibliográfica e, em seguida, promove-se a coleta e análise de dados segundo uma adaptação de métodos empíricos com normas de usabilidade. Os resultados indicam uma insuficiência dos instrumentos de referência online das instituições arquivísticas para atingir seu amplo público, em que pesem os critérios de inteligibilidade, operacionalidade e satisfação dos usuários.

Ao longo da leitura dos trabalhos convidamos todos a discussão, reflexão e aprimoramento das mais variadas questões em nosso campo de conhecimento.

Porto Alegre, 22 de janeiro de 2020.

Thiago Henrique Bragato Barros

Coordenador da IV REPARQ 